\title{
Concentration levels and an assessment of human health risk of polycyclic aromatic hydrocarbons (PAHs) and polychlorinated biphenyls (PCBs) in honey and pollen
}

\section{Mehmet Ferhat Sari}

Bursa Uludağ Üniversitesi: Bursa Uludag Universitesi

Fatma Esen ( $\sim$ payan@uludag.edu.tr)

Bursa Uludag Universitesi https://orcid.org/0000-0002-1445-0868

\section{Research Article}

Keywords: PAHs, PCBs, pollen, honey, risk assessment

Posted Date: February 10th, 2022

DOI: https://doi.org/10.21203/rs.3.rs-1234555/v1

License: (c) (1) This work is licensed under a Creative Commons Attribution 4.0 International License. Read Full License 


\section{Abstract}

Persistent organic pollutants (POPs) such as polycyclic aromatic hydrocarbons (PAHs) and polychlorinated biphenyls (PCBs) accumulate in the food chain due to their physical and chemical properties and adversely affect human health. For this reason, this study aimed to determine the PAH and PCB concentration levels in pollen and honey samples in urban and semi-urban areas and to evaluate the risk of cancer that may occur by ingestion in Bursa, Turkey. The average total concentrations of $14 \mathrm{PAH}$ $\left(\sum_{14} \mathrm{PAH}\right)$ compounds in pollen and honey samples were found to be $304.3 \pm 192.3 \mathrm{ng} / \mathrm{g}$ (average \pm standard deviation) and $650.2 \pm 118.1 \mathrm{ng} / \mathrm{g}$ for the urban area, and $329.6 \pm 160.6 \mathrm{ng} / \mathrm{g}$ and $464.3 \pm 66.4 \mathrm{ng} / \mathrm{g}$ for the semi-urban area, respectively. Similarly, $\sum_{14} \mathrm{PCB}$ concentrations in pollen and honey samples were found to be $8.7 \pm 3.6 \mathrm{ng} / \mathrm{g}$ and $13.0 \pm 4.8 \mathrm{ng} / \mathrm{g}$ for the urban area, and $7.7 \pm 2.2 \mathrm{ng} / \mathrm{g}$ and $17.4 \pm 4.0 \mathrm{ng} / \mathrm{g}$ for the semi-urban area, respectively. It was determined that the pollen and honey samples in both sampling areas were affected by local PCB sources. Finally, while there was no cancer risk for PCBs due to ingestion of honey and pollen in both sampling areas, acceptable cancer risk has been calculated for PAHs.

\section{Introduction}

Food safety is a crucial issue for food health and economics in developed and developing countries (Bolek 2020). Also, the main objective of food safety includes protecting the health of consumers and their confidence in basic foods (Schröder et al. 2016; Bonerba et al. 2021). In parallel with the increase in population, the demand for basic food products is increasing day by day (Ruby et al. 2019). However, rapidly increasing industrialization causes deterioration in the environment and ecosystem, leading to pollution of basic food products (Altunay et al., 2019). It is essential to monitor pollutants in basic food products such as honey and pollen to prevent health risks that may occur due to human consumption of food (Panseri et al. 2020).

Studies on persistent organic pollutants (POPs) such as polycyclic aromatic hydrocarbons (PAHs) and polychlorinated biphenyls (PCBs) are increasing each day due to their permanence, biological accumulation, toxicity, long-distance atmospheric transport, and adverse effects on human health (Fu et al. 2018; Qiu et al. 2019). PAHs and PCBs are highly persistent in living things and the environment because of their high bioaccumulative and lipophilic properties (Medehouenou et al. 2011). They accumulate in the food chain due to their physical and chemical properties and affect human health negatively (Mamontova et al. 2017). Although most POPs such as PBCs were banned in the 1970s and the 2000s, they are still found at a significant level in food today (Suarez-Lopez et al. 2019).

Increasing environmental pollution due to industrial developments affects living life, such as soil, air, water, and plants. Honey bees (Apis mellifera L.) go out of the hives approximately ten times a day to collect nectar and pollen from flowers every day in an area of $7 \mathrm{~km}^{2}$ (Rissato et al. 2007). During this process, various microorganisms, particulates, pesticides, and chemicals are kept in the bodies of honey bees and transported by the honey bees to pollen and honey (Rissato et al. 2007; Calatayud-Vernich et al. 
2018). Honey is a natural food consisting of amino acids, sugars and enzymes, organic acids, vitamins, carotenoids, minerals, and aromatic substances (Da Silva et al. 2016). Honey, used as flavoring and sweetener in many foods and beverages, has been known for its nutritional and therapeutic values since ancient times (Meo et al. 2017). Pollen is frequently used as a functional food by humans as it contains high amounts of compounds such as amino acids, antioxidants, vitamins, and lipids (Ares et al. 2018). Pollen is frequently referred to as "the world's best food products" (Kieliszek et al. 2018).

Consumption of honey has increased significantly in the last 25 years due to its healing properties and high nutritional values(Huang et al. 2020). Turkey is the world's second-largest honey-producing country, with approximately 105727 tons of annual honey production (Tornuk et al. 2013; Cengiz et al. 2018). Also, according to the Food and Agriculture Organization of the United Nations (FAO), Turkey's daily consumption of honey is the sixth most consuming country in the world, with 3.3 grams (FAO, 2017). Also, there are many studies in the world and Turkey in which the concentration values of POPs on honey are determined (Al-Alam et al., 2019; Al-Waili et al., 2012; Bargańska et al., 2016; Chiesa et al., 2016; dos Santos et al., 2021; Erdoğrul, 2007; Kargar et al., 2017; Panseri et al., 2020; Roszko et al., 2016). However, although there are few studies in the literature for calculating the cancer risk for PAHs based on honey and pollen ingestion, there are no studies in which there is an estimation of cancer risk for PCBs based on honey and pollen ingestion.

The purposes of this study were i) to determine PAH and PCB concentration in pollen and honey samples, ii) identification of possible sources of PAHs and PCBs, and iii) to evaluate the risk of cancer that may occur by ingestion.

\section{Material And Methods}

\subsection{Sampling areas and sampling program}

This study was conducted from May to September 2017 in the Ovaakca (Urban) and Cumalikizik (Semiurban) areas within the borders of Bursa (Turkey). The Ovaakca sampling area (40 17'11.16 "N - $29^{\circ}$ $5^{\prime} 13.20$ "E) represents an urban area since it is approximately $1.5 \mathrm{~km}$ from the nearest highway, $3 \mathrm{~km}$ from Industrial Zone, and $500 \mathrm{~m}$ from the settlement. Similarly, the Cumalikizik sampling area $\left(40^{\circ}\right.$ $\left.10^{\prime} 8.30 \mathrm{~N} \mathrm{~N}-29^{\circ} 10^{\prime} 26.82 \mathrm{~N} \mathrm{E}\right)$ represents a semi-urban area since it is $2 \mathrm{~km}$ from the nearest highway and 3 $\mathrm{km}$ from the residential area.

Pollen samples were collected between May and September 2017, and honey samples were collected between July and September 2017 when the honey production was excessive. Both pollen and honey samples were taken from hives raised by two volunteer beekeepers in monthly 2-weeks periods. Two weeks were chosen as the sampling period. Thus, a total of ten pollen and six honey samples were obtained for a sampling area. The samples were collected homogeneously from at least 5-6 different beehives to represent the whole area and made into a single sample. In order to prevent any pollution that may occur during the transportation of the samples and bringing them to the laboratory environment, 
they were wrapped in aluminum foils and placed in closed bags. Samples brought to the laboratory were stored in freezers at $-20^{\circ} \mathrm{C}$ until extractions.

\subsection{Extraction, clean-up, and fraction}

The extraction, clean-up, and fraction processes of the pollen and honey samples were reported previously (Sari et al., 2020). Briefly, two grams of pollen samples were taken into bottles and crushed thoroughly. $50 \mathrm{~mL}$ of dichloromethane (Merck, Darmstadt, Germany)/petroleum ether (Merck, Darmstadt, Germany) (DCM/PE) (1/1, v/v) mixture was added to the crushed samples. Approximately $1 \mathrm{gram}$ of the weighed honey sample was dissolved in $10 \mathrm{~mL}$ distilled water (Lambert et al., 2012; Sari et al., 2020). Then, $1 \mathrm{~mL}$ surrogate standard (Acenaphthene-d10, Chrysene-d12, Naphthalene-d8, Perylene-d12, and Phenanthrene-d10 for PAHs, and PCB\#14, PCB\#65 and PCB\#166 for PCBs) was added to this solvent in order to determine the recovery efficiency values of the samples. The pollen samples were shaken for about 2 hours (Sari et al., 2020; Tasdemir and Esen, 2008). The sample bottles were then taken into an ultrasonic bath (Elmasonic S $80 \mathrm{H}$, Germany) and extracted for 15 minutes. The dissolved honey samples were transferred to the separatory funnel and $50 \mathrm{~mL}$ methanol $(\mathrm{MeOH}), 50 \mathrm{~mL}$ saturated salt solution, 50 $\mathrm{mL}$ distilled water and $40 \mathrm{~mL}$ DCM were added, respectively. Then, the honey samples were shaken for about half an hour (Evci et al. 2016). The pollen and honey samples extracted were concentrated using a rotary evaporator (Laborota 4001 Model, Heidolph, Germany). The rotary evaporator operating at 30-35 rpm and $22-23{ }^{\circ} \mathrm{C}$ reduced their volumes to approximately $2 \mathrm{~mL}$ (Esen et al. 2008). Thus, the solvent in the sample was converted to hexane (HEX) (Merck, Darmstadt, Germany). Until the next stage, the sample bottles were stored in the freezer at $-20^{\circ} \mathrm{C}$.

The samples were fractionated by using glass fiber wool, 3 grams of silicic acid (\%3 pure water), 2 grams of alumina (\%6 pure water), and 2 grams of sodium sulfate $\left(\mathrm{Na}_{2} \mathrm{SO}_{4}\right)$ (Merck, Darmstadt, Germany) (Esen et al., 2017). The column was first purged with $20 \mathrm{~mL}$ of DCM followed by $20 \mathrm{~mL}$ of PE. Subsequently, 2 $\mathrm{mL}$ volumes of samples were passed through the column. $25 \mathrm{~mL}$ PE was used for the elution of target PCBs (fraction 1), and $20 \mathrm{~mL}$ DCM was used for the elution of target PAHs (fraction 2) (Sari et al., 2020; Esen et al., 2017). The samples were fractionated, separated, and then their volume was reduced to $5 \mathrm{~mL}$ with the rotary evaporator operating at $30-35 \mathrm{rpm}$ and $22-23^{\circ} \mathrm{C}$. Finally, after adding $15 \mathrm{~mL}$ of HEX to the samples, their volume was reduced to $2 \mathrm{~mL}$ (Esen et al., 2017).

\subsection{Instrumental analysis}

PAHs were determined using a gas chromatograph (GC) (Agilent 7890A) device with a mass spectrometer (MS) (Agilent 5975C) and PCBs were determined using a GC device with a micro-electron capture detector $(\mu \mathrm{ECD})$. Field blanks with a ratio of at least $10 \%$ of the samples were collected to determine possible contamination during the transportation, storage, and preparation of the samples. The Agilent 7890A$\mu E C D$ instrument determined the mass values of pollen and honey samples and blank samples. Helium gas was used as the carrier gas at a flow rate of $1.9 \mathrm{~mL} / \mathrm{min}$, and high purity nitrogen gas was used as the make-up gas with helium gas. In this study, 16 different PAHs "(Naphthalene (Nap), Acenaphthylene (Acy), Acenaphthene (Ace), Fluorene (FIn), Phenanthrene (Phe), Anthracene (Ant), Fluoranthene (FI), 
Pyrene (Py), Benz(a)anthracene (BaA), Chrysene (Chr), Benzo(b)fluoranthene (BbF), Benzo(k)fluoranthene (BkF), Benzo(a)pyrene (BaP), Indeno(1,2,3-c,d)pyrene (IcdP), Dibenz(a,h)anthracene (DahA) ve Benzo(g,h,i)perylene (BghiP))" were analyzed. Similarly, 8 different dioxin-like PCBs (dl-PCBs) (PCB\#81, 105, 114, 118, 126, 156, 167 and 169) and 6 different non-dioxin-like PCBs (Ndl-PCBs) (PCB\#28, 52, 101, 138,153 and 180) were analyzed. Pearson correlation analysis and all figures were created in the SigmaPlot@ version 13.0 .

\subsection{Quality assurance/Quality control (QA/QC)}

All glass materials used during the experiment were washed with special detergent water and rinsed under tap water. The rinsed materials were washed with pure water, ACE, and PE, respectively, and kept in the oven at $105^{\circ} \mathrm{C}$ for approximately 24 hours. After the glass materials were dried, they were wrapped in aluminum foil and stored until use. In the GC-MS and GC- $\mu$ ECD analysis, calibration standards at six different concentration levels were used during the calibration process. All calibration standards were prepared in HEX. Concentration values of prepared calibration standards were $0.2,0.5,1.0,2.0,5.0$ and $10.0 \mu \mathrm{g} / \mathrm{mL}$ for PAHs, and 1.0, 2.5, 5.0, 10.0, 25.0 and $40.0 \mathrm{ng} / \mathrm{mL}$ for PCBs. $\mathrm{R}^{2}$ values for all calibration levels were calculated as higher than 0.99 . The calibration of the GC-MS and GC- $\mu \mathrm{ECD}$ was tested with a medium calibration standard for approximately every 100 samples. At least $10 \%$ of the blank samples were taken to determine the contamination that may occur during the taking of samples to the laboratory and analysis. Blank samples of the pollen and honey were obtained by considering 2 grams of $\mathrm{Na}_{2} \mathrm{SO}_{4}$ (Sari et al., 2020).

The instrumental detection limits (IDLs), which are the calibration standard concentration value at the lowest concentration level perceived by the device, are determined according to the Signal: Noise (S: $N$ ) ratio of the 3:1. The IDL values for $1 \mu \mathrm{L}$ injection were $0.1 \mathrm{pg}$ for PAHs and $0.15 \mathrm{pg}$ for PCBs. The method of detection limits was calculated as the average mass values of the blank samples plus three times the standard deviation (Esen et al., 2017; Sari et al., 2020). The MDL values for sampling points ranged from $24.7 \mathrm{pg}$ to $53.83 \mathrm{pg}$ for PAHs and from $0.26 \mathrm{pg}$ to $9.18 \mathrm{pg}$ for PCBs. If any POP compounds had less than $M D L$ values, then the concentration of that congener would have taken as half of the IDL values for statistical calculations. The surrogate standard was used to determine the recovery efficiencies. Average recovery efficiencies in all samples were higher than $60 \%$ except Nap and Acy. Nap and Acy were not included in the calculations of these compounds due to their low recovery efficiency $(<60 \%)$.

\section{Results And Discussion}

\subsection{PAH concentration in pollen and honey}

Pollen and honey samples were taken from the urban and semi-urban areas to determine the total PAH concentrations in Bursa between May-September 2017. The concentrations of total $14 \mathrm{PAH}\left(\sum_{14} \mathrm{PAHs}\right)$ compounds in pollen and honey samples were found to be $304.3 \pm 192.3 \mathrm{ng} / \mathrm{g}$ (ranged from 146.8 to $623.1 \mathrm{ng} / \mathrm{g}$ ) and $650.2 \pm 118.1 \mathrm{ng} / \mathrm{g}$ (ranged from 514.0 to $723.4 \mathrm{ng} / \mathrm{g}$ ) for the urban area, respectively. 
Similarly, for the semi-urban area, concentrations were found to be $329.6 \pm 160.6 \mathrm{ng} / \mathrm{g}$ (ranged from 194.7 to $598.6 \mathrm{ng} / \mathrm{g}$ ) and $464.3 \pm 66.4 \mathrm{ng} / \mathrm{g}$ (ranged from 413.1 to $539.3 \mathrm{ng} / \mathrm{g}$ ), respectively (Figure 1).

The lowest PAH concentrations in pollen samples were measured in August for the urban area and July for the semi-urban area. The highest PAH concentrations were measured in May for both sampling areas. Concentration levels in urban and semi-urban areas were generally measured low in the summer months. Plants are affected by both soil pollution and the atmosphere from PAH sources. Therefore, PAH concentrations in pollen samples are expected to vary depending on both present and old pollution of the soil (Lambert et al. 2012). The high PAH concentration in the pollen samples collected from the semiurban area can be explained by the diversity of plant species grown in the region due to the presence of more species that are absorbed by PAHs. In a study conducted by Lambert et al. (2012), measured PAH4 concentration levels in pollen samples ranged from 0.33 to $129.41 \mathrm{ng} / \mathrm{g}$ in France. In our study, the PAH4 concentrations for the urban and semi-urban areas ranged from 8.23 to $72.38 \mathrm{ng} / \mathrm{g}$ and 16.27 to 135.40 $\mathrm{ng} / \mathrm{g}$, respectively. Since there are a limited number of studies in the literature in which PAHs were determined in pollen samples, further comparison with concentration values could not be made.

The highest PAH concentrations in honey samples for the urban area were observed in July, and the lowest PAH concentrations in August. In the semi-urban area, the highest PAH concentrations in honey samples were observed in September and the lowest PAH concentrations in July. A study conducted by Iwegbue et al. (2016) measured $\sum_{16} \mathrm{PAH}$ concentration levels ranging from 180 to $641 \mathrm{ng} / \mathrm{g}$ in industrial areas in Niger Delta, Nigeria. In another study conducted by Lambert et al. (2012), measured PAH4 concentration levels in honey samples ranged from 0.03 to $5.80 \mathrm{ng} / \mathrm{g}$ in France. A study conducted by Petrović et al. (2019) measured PAH4 concentration levels ranging from LOD $(0.32 \mathrm{ng} / \mathrm{g})$ to $362.40 \mathrm{ng} / \mathrm{g}$ in honey samples from supermarkets and open markets in Serbia. In this study, the concentration levels measured in similar PAH compounds for the urban and semi-urban areas ranged from 47.98 to 75.94 $\mathrm{ng} / \mathrm{g}$ and 17.33 to $55.40 \mathrm{ng} / \mathrm{g}$, respectively. A study conducted by Ozoani et al. (2020) measured $\sum_{16} \mathrm{PAH}$ concentration levels ranged from 0.251 to $3.07 \mathrm{mg} / \mathrm{kg}$ for the urban area and ranged from 1.30 to 3.08 $\mathrm{mg} / \mathrm{kg}$ for the semi-urban area in Nigeria.

\subsection{PCB concentration in pollen and honey}

The concentration of total dioxin-like PCBs (dl-PCBs) and non-dioxin-like PCBs (Ndl-PCBs) in pollen were found to be $2.8 \pm 0.8 \mathrm{ng} / \mathrm{g}$ (ranged from 1.9 to $4.1 \mathrm{ng} / \mathrm{g}$ ) and $5.6 \pm 2.8 \mathrm{ng} / \mathrm{g}$ (ranged from 2.2 to $8.5 \mathrm{ng} / \mathrm{g}$ ) for the urban area, $3.9 \pm 1.3 \mathrm{ng} / \mathrm{g}$ (ranged from 2.4 to $5.8 \mathrm{ng} / \mathrm{g}$ ) and $3.5 \pm 1.2 \mathrm{ng} / \mathrm{g}$ (ranged from 2.4 to 5.6 $\mathrm{ng} / \mathrm{g}$ ) for the semi-urban area, respectively. Similarly, the concentration of dl-PCBs and Ndl-PCBs in honey were found to be $6.9 \pm 2.3 \mathrm{ng} / \mathrm{g}$ (ranged from 4.3 to $8.6 \mathrm{ng} / \mathrm{g}$ ) and $6.2 \pm 0.9 \mathrm{ng} / \mathrm{g}$ (ranged from 5.9 to 6.9 $\mathrm{ng} / \mathrm{g}$ ) for the urban area, $5.9 \pm 1.5 \mathrm{ng} / \mathrm{g}$ (ranged from 4.3 to $7.1 \mathrm{ng} / \mathrm{g}$ ) and $10.5 \pm 3.0 \mathrm{ng} / \mathrm{g}$ (ranged from 7.7 to $13.7 \mathrm{ng} / \mathrm{g}$ ) for the semi-urban area, respectively (Figure 2).

Considering the studies in which the PCBs in the pollen and honey samples in the literature are determined, Roszko et al. (2016) reported that dl-PCB and Ndl-PCB concentrations in pollen samples were $74.0 \mathrm{pg} / \mathrm{g}$ and $194.0 \mathrm{pg} / \mathrm{g}$, respectively in Poland. Erdoğrul (2007) reported that Ndl-PCB concentrations 
in honey samples ranged from $1.12 \mathrm{ng} / \mathrm{g}$ to $1.48 \mathrm{ng} / \mathrm{g}$ in Kahramanmaras province in Turkey. Herrera et al. (2005) reported that maximum dl-PCB concentrations in honey samples ranged from $4.3 \mathrm{ng} / \mathrm{g}$ (PCB\#180) to $593.7 \mathrm{ng} / \mathrm{g}$ (PCB\#28) near an industrial site in Spain. Chiesa et al. (2016) reported that dlPCB concentrations in honey samples ranged from $0.27 \mathrm{ng} / \mathrm{g}$ (PCB\#28) to $0.92 \mathrm{ng} / \mathrm{g}$ (PCB\#138) in South Italy. The concentration levels obtained in this study were similar to the various studies in the literature.

Ndl-PCB concentrations in pollen samples in the urban area were measured higher than $\mathrm{dl}-\mathrm{PCB}$ concentrations in all other months except in September. In contrast, Ndl-PCB concentrations in honey samples in the urban area were measured lower than dl-PCB concentrations in all other months except August. In pollen samples in the semi-urban area, there was no significant difference between dl-PCB and Ndl-PCB concentrations (t-test, $p>0.05$ ). In honey samples, Ndl-PCBs were dominant in all months in the semi-urban area (Figure 2). Percentage distributions of dl-PCB and Ndl-PCB in pollen and honey samples were presented in both sampling areas for better explanation in Figure 3.

According to the percentage distribution of DI-PCBs, PCB\#169 (ranged from 27.0-35.9\%) is the dominant PCB congener for all sampling areas and sampling materials. Similarly, percentage distribution of NdlPCBs in pollen and honey samples, PCB\#180 (ranged from 23.7-42.4\%), and PCB\#52 (ranged from $18.8-37.5 \%)$ are dominant PCB congeners in both sampling areas. In honey samples, PCB\#180 (40.4\%) and PCB\#138 $(20.0 \%)$ are the dominant PCB congeners in the urban sampling area, while PCB\#52 (37.5\%) and PCB\#180 (31.2\%) are the dominant PCB congeners in the semi-urban area. In the study conducted by Erdoğrul (2007), the dominant PCB congeners in honey samples are PCB\#52 and PCB\#28, whereas, in the study conducted by Herrera et al. (2005), the dominant PCB congeners in honey samples are PCB\#28 and PCB\#138. In addition, in the study conducted by Chiesa et al. (2016), it was stated that the most dominant PCB congener is PCB\#138 in honey samples. In the studies by Herrera et al. (2005) and Chiesa et al. (2016), industrial activities near the sampling areas. In the study conducted by Erdoğrul (2007), the sampling area is relatively far from industrial activities. It has been thought that the differences between the sampling areas may cause differences between the PCBs. In a study conducted by Rozsko et al. (2016), it was stated that the differences between PCB congeners are due to long-range air transport, accumulation on plant surfaces, and the distribution/transport of pollutants in the environment. Also, high chlorinated PCB congeners such as PCB\#180 have lower evaporation properties compared to low chlorinated PCB congeners such as PCB\#28. Therefore, the predominance of lowchlorinated PCBs is due to atmospheric deposition, whereas the predominance of high-chlorinated PCBs is due to the effectiveness of local resources (de Souza et al. 2018). Since high chlorinated PCBs from both dl-PCB and Ndl-PCB congeners are predominant, local resources are thought to be more effective in pollen and honey samples from both sampling areas.

\subsection{Health Risk Assessment of PAHs and PCBs}

Food consumption is defined as the main pathway for humans to be exposed to pollutants (Khillare et al. 2012). Rapidly increasing industrialization causes adverse effects on the ecosystem and the environment, which leads to food pollution (Altunay et al., 2019). Foods contaminated with POPs are present a high probability of posing a potential health risk for the consumers (Rusin et al. 2019). 
Exposure to PAH and PCBs in various ways; causes carcinogenic effects, neurological and immunological problems, and other adverse health effects (Fu et al. 2018). Cancer risk calculation refers to the Incremental Lifetime Cancer Risk (ILCR) calculated using the food ingestion dose with the following Equation (1) (Wang et al. 2019);

$$
\mathrm{ILRC}=\frac{\mathrm{C}_{\mathrm{i}} \times \mathrm{DC} \times \mathrm{CSF} \times \mathrm{EF} \times \mathrm{ED}}{\mathrm{BW} \times \mathrm{AT}} \times 10^{-6}
$$

where, $\mathrm{Ci}$ is the average ith PAH and PCB congeners concentration for pollen and honey samples in the urban and semi-urban area ( $\mathrm{ng} / \mathrm{g})$, DC is the daily consumption of pollen $(1.4 \mathrm{~g} /$ day) and honey (3.3 $\mathrm{g} /$ day) (FAO, 2017), CSF is the cancer slope factor (7.3 day. $\mathrm{kg} / \mathrm{mg}$ for PAHs and 2 day.kg/mg for PCBs) (Fu et al. 2018; Ali 2019), $10^{-6}$ is a conversion factor (ng to $\mathrm{mg}$ ), EF and ED are the exposure frequency (180 day/year) and exposure duration (24 years), BW is the body weight (61.5 kg) and AT is the average days (25,550 days) (Ghanavati et al. 2019). According to US-EPA, if the ILCR values are higher than $1 \times 10^{-4}$, there is a high cancer risk, if the ILCR values are between $1 \times 10^{-6}$ and $1 \times 10^{-4}$, there is an acceptance of cancer risk, and if the ILCR values are lower than $1 \times 10^{-6}$, there is a non-cancer risk (Wang et al. 2019). The carcinogenic risk results obtained in this study were given in Table 1.

Table 1

Carcinogenic risk for PAHs and PCBs via digestion of honey and pollen $\left(\times 10^{-6}\right)$

\begin{tabular}{|lllll|}
\hline & \multicolumn{2}{l}{ Urban Area } & \multicolumn{2}{l|}{ Semi-Urban Area } \\
\hline & Pollen & Honey & Pollen & Honey \\
\hline PAHs & & & & \\
\hline Minimum & 0.12 & 0.27 & 0.13 & 0.74 \\
\hline Maximum & 1.06 & 3.45 & 0.97 & 2.31 \\
\hline Mean & 0.54 & 1.97 & 0.61 & 1.78 \\
\hline dl-PCBs & & & & \\
\hline Minimum & 0.01 & 0.07 & 0.01 & 0.05 \\
\hline Maximum & 0.11 & 0.85 & 0.13 & 0.12 \\
\hline Mean & 0.05 & 0.18 & 0.05 & 0.09 \\
\hline Ndl-PCBs & & & & \\
\hline Minimum & 0.08 & 0.05 & 0.09 & 0.06 \\
\hline Maximum & 0.57 & 0.63 & 0.69 & 0.51 \\
\hline Mean & 0.36 & 0.29 & 0.41 & 0.23 \\
\hline
\end{tabular}


According to the calculated ILCR values for pollen and honey samples, PCBs did not pose any risk for both sampling areas. However, the calculated cancer risk among PAHs was found to be within an acceptable cancer risk. This situation is thought to be due to the use of smoke in the collection of samples. In general, lower ILCR values were obtained in pollen samples compared to honey samples for both PAHs and PCBs. Cancer risk has been calculated for PCB concentrations in honey and pollen samples, but no study has been found to compare with the literature. In a study conducted by Iwegbue et al. (2016) in Nigeria, it was stated that there was no risk of cancer as a result of ingestion of honey for PAHs. The reason for the acceptable cancer risk in this study was considering 14 PAH compounds in cancer risk calculations. In addition, due to the limited number of studies in the literature, pesticide residues were compared with the results we obtained. In a study by Blasco et al. (2003), it was stated that pesticides did not pose any risk in honey samples, but in a study by Sanchez-Bayo and Goka (2014), especially lindane $(\mathrm{y}-\mathrm{HCH})$ carries a high risk in honey samples. It is stated that the different results obtained by using the same sampling materials, especially the concentrations of the OCPs and the pollutant profiles, vary according to the areas (Thompson et al. 2017).

\section{Conclusion}

In this study, the concentration levels of PAHs and PCBs, and cancer risks that may occur as a result of the consumption of pollen and honey were evaluated in the urban and semi-urban areas in Bursa. PAH and PCB concentrations were measured close to each other in pollen and honey samples in both sampling areas. Besides, the concentration values obtained were similar to those previously conducted in the literature. According to the cancer risk calculations developed by the US-EPA, the cancer risk for PCBs due to ingestion of honey and pollen was not determined in either sampling area, while the cancer risk values for PAHs were within the acceptable range. On the other hand, this situation causes the smoke used during the collection of samples to slightly increase the PAH concentrations and, accordingly, the risk of cancer to be slightly higher. Since this study is one of the first to evaluate the health risk of PAHs and PCBs in pollen and honey samples, it is thought to guide future studies. Also, we recommend that researchers who want to identify POP sources in pollen and honey samples take samples from dominant plant species and soils in the sampling areas.

\section{Declarations}

\section{Ethics approval and consent to participate}

Not Applicable

\section{Consent for publication}

Not Applicable

\section{Availability of data and materials}


The datasets used and/or analysed during the current study are available from the corresponding author on reasonable request.

\section{Competing interests}

The authors declare that they have no known competing financial interests or personal relationships that could have appeared to influence the work reported in this paper.

\section{Funding}

This study was supported by the Turkish Scientific and Technological Research Council (TÜBITAK) (project number 116Y208).

\section{Authors' contributions}

Mehmet Ferhat Sari: Methodology, Software, Formal analysis, Writing - Original Draft, Data Curation.

Fatma Esen: Methodology, Data Curation, Writing - Original Draft, Writing - Review \& Editing, Visualization, Supervision.

\section{Acknowledgments}

We would like to thank Dr. M. Ertan GUNES and Emine GURKAN AYYILDIZ for their successful help in the sampling and laboratory section.

\section{References}

1. Al-Alam J, Fajloun Z, Chbani A, Millet M (2019) Determination of 16 PAHs and 22 PCBs in honey samples originated from different region of Lebanon and used as environmental biomonitors sentinel. J Environ Sci Heal - Part A Toxic/Hazardous Subst Environ Eng 54:9-15. https://doi.org/10.1080/10934529.2018.1500782

2. Al-Waili N, Salom K, Al-Ghamdi A, Ansari MJ (2012) Antibiotic, pesticide, and microbial contaminants of honey: Human health hazards. Sci World J 2012. https://doi.org/10.1100/2012/930849

3. Ali N (2019) Polycyclic aromatic hydrocarbons (PAHs) in indoor air and dust samples of different Saudi microenvironments; health and carcinogenic risk assessment for the general population. Sci Total Environ 696:133995. https://doi.org/10.1016/j.scitotenv.2019.133995

4. Altunay N, Elik A, Gürkan R (2019) Monitoring of some trace metals in honeys by flame atomic absorption spectrometry after ultrasound assisted-dispersive liquid liquid microextraction using natural deep eutectic solvent. Microchem J 147:49-59. https://doi.org/10.1016/j.microc.2019.03.003

5. Ares AM, Valverde S, Bernal JL et al (2018) Extraction and determination of bioactive compounds from bee pollen. J Pharm Biomed Anal 147:110-124. https://doi.org/10.1016/j.jpba.2017.08.009 
6. Bargańska Z, Ítlebioda M, Namies̈nik J (2016) Honey bees and their products: Bioindicators of environmental contamination. Crit Rev Environ Sci Technol 46:235-248. https://doi.org/10.1080/10643389.2015.1078220

7. Blasco C, Fernández M, Pena A et al (2003) Assessment of Pesticide Residues in Honey Samples from Portugal and Spain. J Agric Food Chem 51:8132-8138. https://doi.org/10.1021/jf034870m

8. Bolek S (2020) Consumer knowledge, attitudes, and judgments about food safety: A consumer analysis. Trends Food Sci Technol 102:242-248. https://doi.org/10.1016/j.tifs.2020.03.009

9. Bonerba E, Panseri S, Arioli F et al (2021) Determination of antibiotic residues in honey in relation to different potential sources and relevance for food inspection. Food Chem 334:127575. https://doi.org/10.1016/j.foodchem.2020.127575

10. Calatayud-Vernich P, Calatayud F, Simó E, Picó Y (2018) Pesticide residues in honey bees, pollen and beeswax: Assessing beehive exposure. Environ Pollut 241:106-114. https://doi.org/10.1016/j.envpol.2018.05.062

11. Cengiz MM, Tosun M, Topal M (2018) Determination of the physicochemical properties and $13 \mathrm{C} / 12 \mathrm{C}$ isotope ratios of some honeys from the northeast Anatolia region of Turkey. $\mathrm{J}$ Food Compos Anal 69:39-44. https://doi.org/10.1016/j.jfca.2018.02.007

12. Chiesa LM, Labella GF, Giorgi A et al (2016) The occurrence of pesticides and persistent organic pollutants in Italian organic honeys from different productive areas in relation to potential environmental pollution. Chemosphere 154:482-490. https://doi.org/10.1016/j.chemosphere.2016.04.004

13. Cindoruk SS, Esen F, Tasdemir Y (2007) Concentration and gas/particle partitioning of polychlorinated biphenyls (PCBs) at an industrial site at Bursa, Turkey. Atmos Res 85:338-350. https://doi.org/10.1016/j.atmosres.2007.02.004

14. Da Silva PM, Gauche C, Gonzaga LV et al (2016) Honey: Chemical composition, stability and authenticity. Food Chem 196:309-323. https://doi.org/10.1016/j.foodchem.2015.09.051

15. de Souza AC, Taniguchi S, Lopes Figueira RC et al (2018) Historical records and spatial distribution of high hazard PCBs levels in sediments around a large South American industrial coastal area (Santos Estuary, Brazil). J Hazard Mater 360:428-435. https://doi.org/10.1016/j.jhazmat.2018.08.041

16. dos Santos M, Vareli CS, Janisch B et al (2021) Contamination of polychlorinated biphenyls in honey from the Brazilian state of Rio Grande do Sul. Food Addit Contam - Part A Chem Anal Control Expo Risk Assess 38:452-463. https://doi.org/10.1080/19440049.2020.1865578

17. Erdoğrul Ö (2007) Levels of selected pesticides in honey samples from Kahramanmaraş, Turkey. Food Control 18:866-871. https://doi.org/10.1016/j.foodcont.2006.05.001

18. Esen F, Evci YM, Tasdemir Y (2017) Evaluation and application of a passive air sampler for polycylic aromatic hydrocarbons (PAHs). J Environ Sci Heal - Part A Toxic/Hazardous. Subst Environ Eng 52:1022-1029. https://doi.org/10.1080/10934529.2017.1328949 
19. Esen F, Tasdemir Y, Vardar N (2008) Atmospheric concentrations of PAHs, their possible sources and gas-to-particle partitioning at a residential site of Bursa, Turkey. Atmos Res 88:243-255. https://doi.org/10.1016/j.atmosres.2007.11.022

20. Evci YM, Esen F, Taşdemir Y (2016) Monitoring of Long-Term Outdoor Concentrations of PAHs with Passive Air Samplers and Comparison with Meteorological Data. Arch Environ Contam Toxicol 71:246-256. https://doi.org/10.1007/s00244-016-0292-6

21. (Food FAO, and Agriculture Organization of the United Nations) (2017). Largest consumers of honey. 1-2. [accessed 2020 Oct 1]. http://www.fao.org/3/ca4657en/ca4657en.pdf

22. Fu L, Lu X, Tan J et al (2018) Bioaccumulation and human health risks of OCPs and PCBs in freshwater products of Northeast China. Environ Pollut 242:1527-1534. https://doi.org/10.1016/j.envpol.2018.08.046

23. Ghanavati N, Nazarpour A, Watts MJ (2019) Status, source, ecological and health risk assessment of toxic metals and polycyclic aromatic hydrocarbons (PAHs) in street dust of Abadan. Iran Catena 177:246-259. https://doi.org/10.1016/j.catena.2019.02.022

24. Herrera A, Pérez-Arquillué C, Conchello P et al (2005) Determination of pesticides and PCBs in honey by solid-phase extraction cleanup followed by gas chromatography with electron-capture and nitrogen-phosphorus detection. Anal Bioanal Chem 381:695-701. https://doi.org/10.1007/s00216004-2924-3

25. Huang F, Song H, Guo L et al (2020) Detection of adulteration in Chinese honey using NIR and ATRFTIR spectral data fusion. Spectrochim Acta - Part A Mol Biomol Spectrosc 235:118297. https://doi.org/10.1016/j.saa.2020.118297

26. Iwegbue CMA, Tesi GO, Obi G et al (2016) Concentrations, health risks and sources of polycyclic aromatic hydrocarbons in Nigerian honey. Toxicol Environ Health Sci 8:28-42. https://doi.org/10.1007/s13530-016-0259-z

27. Kargar N, Matin G, Matin AA, Buyukisik HB (2017) Biomonitoring, status and source risk assessment of polycyclic aromatic hydrocarbons (PAHs) using honeybees, pine tree leaves, and propolis. Chemosphere 186:140-150. https://doi.org/10.1016/j.chemosphere.2017.07.127

28. Khillare PS, Jyethi DS, Sarkar S (2012) Health risk assessment of polycyclic aromatic hydrocarbons and heavy metals via dietary intake of vegetables grown in the vicinity of thermal power plants. Food Chem Toxicol 50:1642-1652. https://doi.org/10.1016/j.fct.2012.01.032

29. Kieliszek M, Piwowarek K, Kot AM et al (2018) Pollen and bee bread as new health-oriented products: A review. Trends Food Sci Technol 71:170-180. https://doi.org/10.1016/j.tifs.2017.10.021

30. Lambert O, Veyrand B, Durand S et al (2012) Polycyclic aromatic hydrocarbons: Bees, honey and pollen as sentinels for environmental chemical contaminants. Chemosphere 86:98-104. https://doi.org/10.1016/j.chemosphere.2011.09.025

31. Mamontova EA, Tarasova EN, Mamontov AA (2017) PCBs and OCPs in human milk in Eastern Siberia, Russia: Levels, temporal trends and infant exposure assessment. Chemosphere 178:239248. https://doi.org/10.1016/j.chemosphere.2017.03.058 
32. Medehouenou TCM, Ayotte P, Carmichael PH et al (2011) Polychlorinated biphenyls and organochlorine pesticides in plasma of older Canadians. Environ Res 111:1313-1320. https://doi.org/10.1016/j.envres.2011.09.017

33. Meo SA, Al-Asiri SA, Mahesar AL, Ansari MJ (2017) Role of honey in modern medicine. Saudi J Biol Sci 24:975-978. https://doi.org/10.1016/j.sjbs.2016.12.010

34. Ozoani HA, Ezejiofor AN, Amadi CN (2020) Safety of honey consumed in Enugu State, Nigeria: a public health risk assessment of lead and polycyclic aromatic hydrocarbons. Rocz Państwowego Zakładu Hig 71:57-66. https://doi.org/10.32394/rpzh.2020.0102

35. Panseri S, Bonerba E, Nobile M et al (2020) Pesticides and environmental contaminants in organic honeys according to their different productive areas toward food safety protection. Foods 9:1-15. https://doi.org/10.3390/foods9121863

36. Petrović J, Kartalović B, Ratajac R et al (2019) PAHs in different honeys from Serbia. Food Addit Contam Part B Surveill 12:116-123. https://doi.org/10.1080/19393210.2019.1569727

37. Qiu YW, Qiu HL, Zhang G, Li J (2019) Bioaccumulation and cycling of organochlorine pesticides (OCPs) and polychlorinated biphenyls (PCBs) in three mangrove reserves of south China. Chemosphere 217:195-203. https://doi.org/10.1016/j.chemosphere.2018.10.188

38. Rissato SR, Galhiane MS, de Almeida MV et al (2007) Multiresidue determination of pesticides in honey samples by gas chromatography-mass spectrometry and application in environmental contamination. Food Chem 101:1719-1726. https://doi.org/10.1016/j.foodchem.2005.10.034

39. Roszko M, Kamińska M, Szymczyk K, J『drzejczak R (2016) Levels of selected persistent organic pollutants (PCB, PBDE) and pesticides in honey bee pollen sampled in Poland. PLoS ONE 11:1-22. https://doi.org/10.1371/journal.pone.0167487

40. Ruby GE, Ungku Zainal Abidin UF, Lihan S et al (2019) A cross sectional study on food safety knowledge among adult consumers. Food Control 99:98-105.

https://doi.org/10.1016/j.foodcont.2018.12.045

41. Rusin M, Dziubanek G, Marchwińska-Wyrwał E et al (2019) PCDDs, PCDFs and PCBs in locally produced foods as health risk factors in Silesia Province, Poland. Ecotoxicol Environ Saf 172:128135. https://doi.org/10.1016/j.ecoenv.2019.01.052

42. Sanchez-Bayo F, Goka K (2014) Pesticide residues and bees - A risk assessment. PLoS ONE 9. https://doi.org/10.1371/journal.pone.0094482

43. Sari MF, Gurkan Ayyildiz E, Esen F (2020) Determination of polychlorinated biphenyls in honeybee, pollen, and honey samples from urban and semi-urban areas in Turkey. Environ Sci Pollut Res 27:4414-4422. https://doi.org/10.1007/s11356-019-07013-w

44. Schröder CHK, Pinhel MFM, Mendonça AO (2016) The Brazilian strategy for monitoring persistent organic pollutants in food obtained from animals. Sci Total Environ 573:1370-1379. https://doi.org/10.1016/j.scitotenv.2016.07.076

45. Suarez-Lopez JR, Clemesha CG, Porta M et al (2019) Organochlorine pesticides and polychlorinated biphenyls (PCBs) in early adulthood and blood lipids over a 23-year follow-up. Environ Toxicol 
Pharmacol 66:24-35. https://doi.org/10.1016/j.etap.2018.12.018

46. Tasdemir Y, Esen F (2008) Deposition of polycyclic aromatic hydrocarbons (PAHs) and their mass transfer coefficients determined at a trafficked site. Arch Environ Contam Toxicol 55:191-198. https://doi.org/10.1007/s00244-007-9096-z

47. Thompson LA, Darwish WS, Ikenaka Y et al (2017) Organochlorine pesticide contamination of foods in Africa: Incidence and public health significance. J Vet Med Sci 79:751-764. https://doi.org/10.1292/jvms.16-0214

48. Tornuk F, Karaman S, Ozturk I et al (2013) Quality characterization of artisanal and retail Turkish blossom honeys: Determination of physicochemical, microbiological, bioactive properties and aroma profile. Ind Crops Prod 46:124-131. https://doi.org/10.1016/j.indcrop.2012.12.042

49. Wang X, Celander MC, Yin X et al (2019) PAHs and PCBs residues and consumption risk assessment in farmed yellow croaker (Larimichthys crocea) from the East China Sea, China. Mar Pollut Bull 140:294-300. https://doi.org/10.1016/j.marpolbul.2019.01.062

\section{Figures}



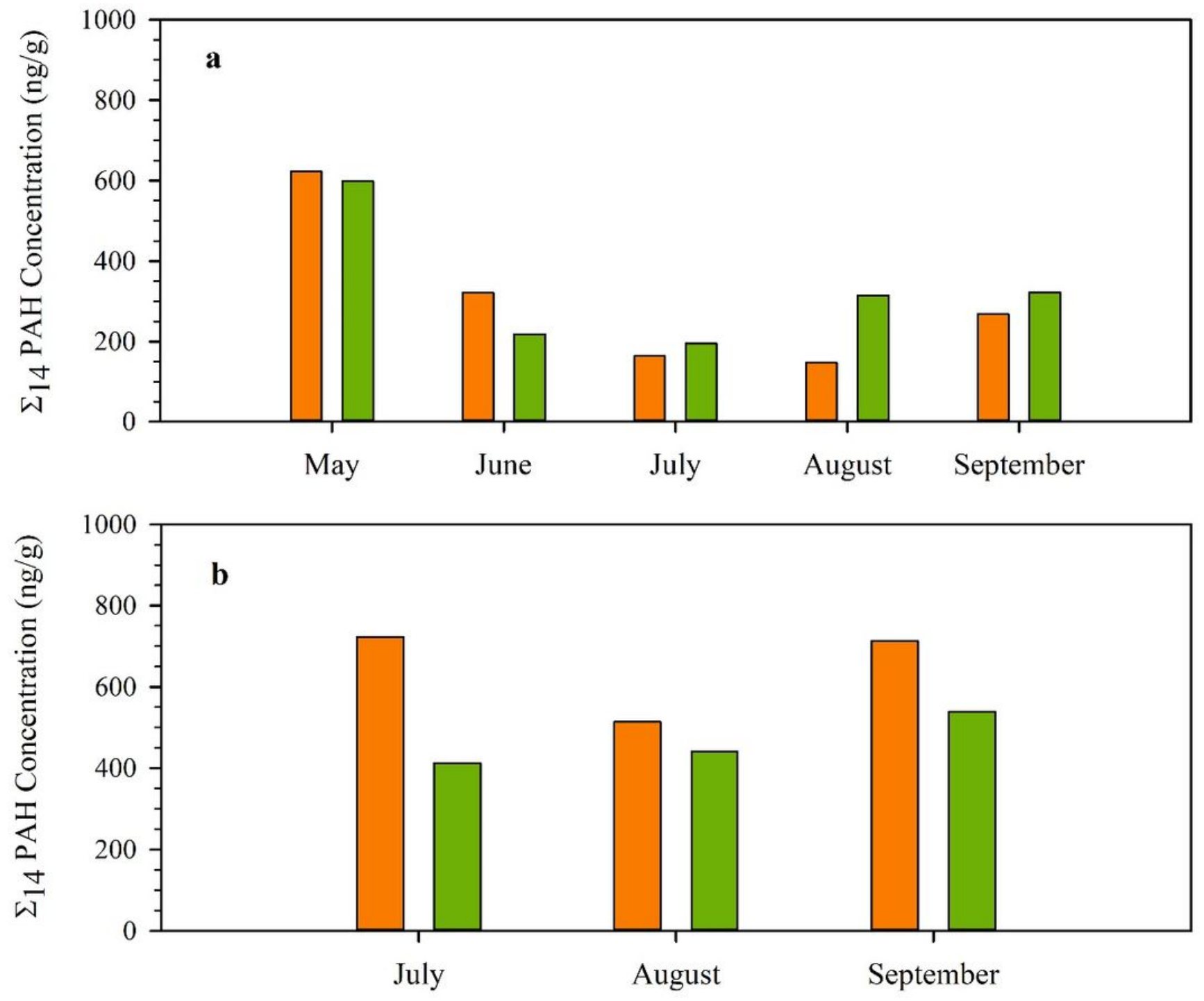

Months

Figure 1

Total PAH concentrations for pollen (a) and honey (b) samples 

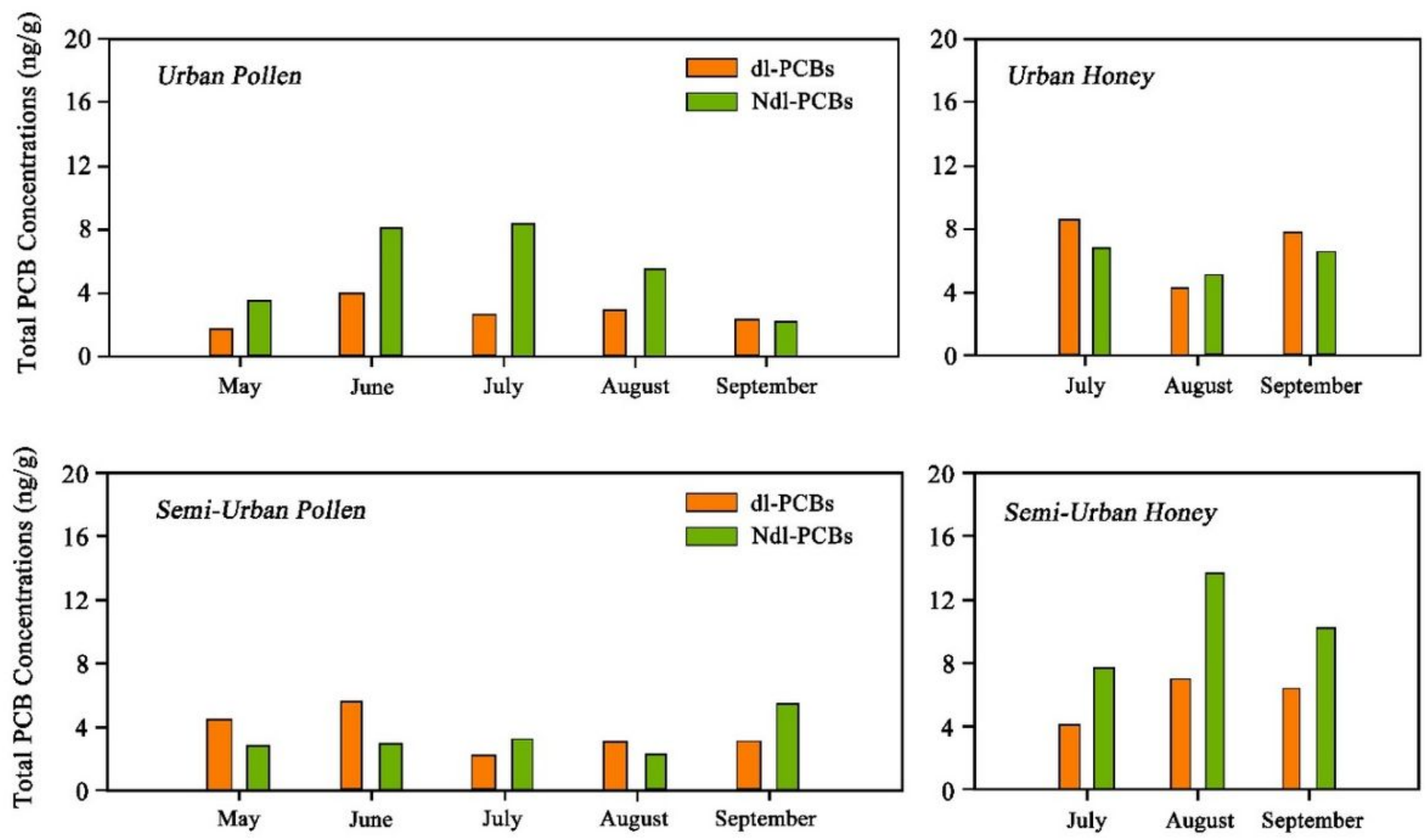

Months

Figure 2

Total dl-PCB and Ndl-PCB concentrations for pollen and honey samples 


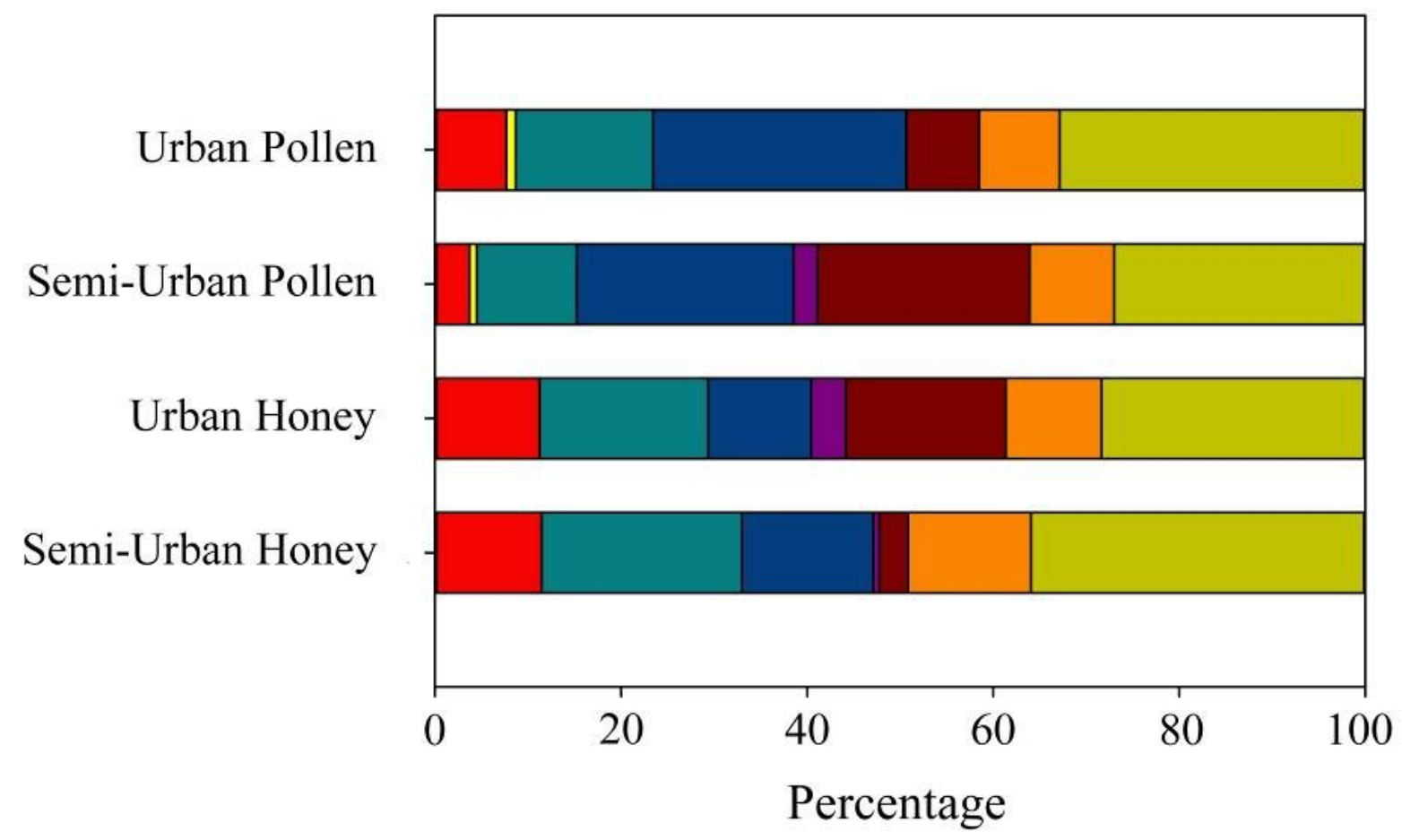

\section{dl-PCBs}

PCB\#81

PCB\#105

PCB\#114

PCB\#118

PCB\#126

PCB\#167

$\square$ PCB\#156

$\square$ PCB\#169

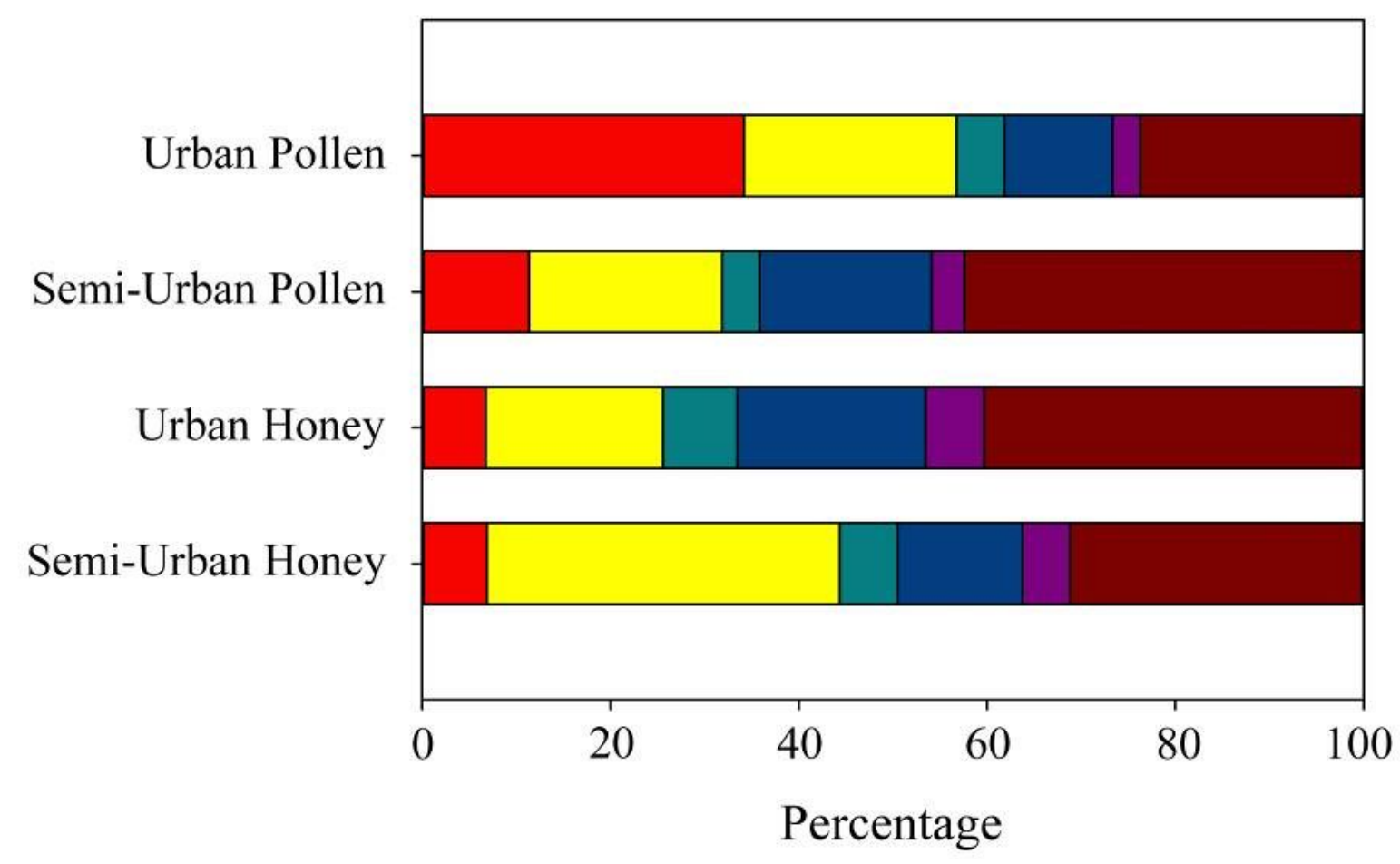

Ndl-PCBs

PCB\#28

PCB\#52

PCB\#101

PCB\#138

PCB\#153

PCB\#180

\section{Figure 3}

Percentage contributions of dl-PCBs and Ndl-PCBs for the pollen and honey samples 